\title{
Damage and failure characteristics of rock similar materials with pre-existing cracks
}

\author{
Xiaoyu Cheng ${ }^{1}$
}

Received: 13 April 2019/Revised: 27 May 2019/Accepted: 12 July 2019/Published online: 22 July 2019

(C) The Author(s) 2019

\begin{abstract}
In order to further study the damage and failure mechanism for rock similar materials, this study investigated the mechanical properties and failure characteristics, law of damage space development, and damage evolution characteristics for rock similar materials with pre-existing cracks of varying length under uniaxial compression load. The equipment used in this study is the self-developed YYW-II strain controlled unconfined compression apparatus and the PCIE-8 acoustic emission monitoring system. Results show that, as the length of pre-existing crack increases: (1) the peak and residual strength reduces, and the peak axial strain and the strain during the initial compression phase increases; (2) the major failure mode is changed from shear failure to tensile failure along a vertical plane that passes the middle of the pre-existing crack; (3) The damage increases during the stable and accelerated development stage, and the effect of the pre-existing cracks is more during the accelerated development stage than the stable development stage.
\end{abstract}

Keywords Pre-existing cracks $\cdot$ Rock similar materials $\cdot$ Mechanical properties $\cdot$ Acoustic emission localization $\cdot$ Damage evolution

\section{Introduction}

Rock is a commonly seen material in geotechnical engineering (Zhou et al. 2014; Cao et al. 2016a, b; Bahaaddini et al. 2013). Cracks in rock heavily influence its stability in geologic structural and engineering activities (Camones et al. 2013; Zhao et al. 2016; Cheng et al. 2016). Cracks in rock have direct influence to its physical and mechanical property, which is directly linked to rock's deformation and failure (Cao et al. 2016a, b; Fan et al. 2015; Lee and Jeon 2011; Manouchehrian et al. 2014).

Lots of researchers have studied the deformation failure characteristics of cracked rock. Park and Bobet (2009) studied the cracks generation, development, extension, and connection, proposed eight crack connection patterns, and

Xiaoyu Cheng

chengxiaoyu89@126.com

1 China Coal Energy Research Institute Co., Ltd., Xi'an 710054, People's Republic of China found the influence of connection pattern to rock sample strength: Wing cracks are tensile cracks that initiate at or near the tip of the flaws, are stable, and propagate towards the direction of maximum compression. Coalescence is produced by the linkage of two flaws by a combination of wing and secondary cracks. The types of coalescence are classified based on the types of cracks that produce linkage, and are closely related to the orientation, spacing, and continuity of the flaws. Nasseri et al. (1997) and Niandou et al. (1997) conducted mechanical test to rock samples with pre-existing cracks, discovered 3 different types of failure modes, and found that the crack angle and the confining pressure are the major factors influencing the failure modes: Quartzitic and Chlorite schists due to presence of continuous weakness planes exhibit "axial cleavage monofracture and multifracture" pattern in unconfined state which is typical of hard fine grained rocks. Where as Quartz mica and Biotite schists due to absence of persistent continuous foliation plane and being coarse grained exhibit "multi shear cataclasis failure pattern". Yang et al. (2009) conducted uniaxial compression test to granite rock 
samples with pre-existing cracks, studied their failure characteristics, and analyzed the influence of crack length, the number of cracks, and crack angle to the sample strength, elasticity modulus, deformation and failure: Compared with the intact marble, the marble with preexisting fissure takes on the localization deformation and asymptotic failure. The peak strength, elastic modulus and peak axial strain of marble with pre-existing fissure are all lower than that of intact marble, and the reduction extent is closely related to the distribution forms of pre-existing fissure. Zhao et al. (2013) studied the influence of crack angle and density to the sample peak strength and crack connection patterns of rock material with multiple, ordered cracks: It is concluded that the transfixion pattern of wing tensile cracks, transfixion pattern of tension-shear cracks between different rows and oblique shear crack transfixion pattern in the same row are the main rapture modes for the ordered multi-crack body. The representative peak strength of specimens decreases with the increasing number of cracks. Li et al. (2004) investigated the crack development and connection mechanism for granite rock samples with pre-existing cracks under uniaxial compression: It is shown that the influence of pre-existing cracks is significant, and the critical collapsing load, failure stress and elastic modulus are all reduced. The orientations of pre-existing cracks can decide which kind of wing cracks will be produced. The interactions between cracks are of marked influence on the initiation and propagation of wing cracks, and make failure manners of samples thoroughly different. Scholz (1968) used 6 acoustic emission (AE) sensors and studied the $\mathrm{AE}$ events spatial distribution in rock samples under uniaxial compression: Many small cracking events or microfractures precede fracture in laboratory compression tests on rock. These observations suggest that the approximate time and place of fracture could have been predicted. In the light of the similarity of microfractures and earthquakes, this suggests a possible method for predicting earthquakes. Zhao et al. (2008) studied the AE events during rock sample failure for different type of rocks, and revealed their failure mechanism: The results showed that failure modes of all samples are the same. During loading, the number of $\mathrm{AE}$ events is minimum in sandy rock but maximum in granite, and both the numbers in sandy rock and red granite change very clearly with no portent of failure to come. The $\mathrm{AE}$ location as a time-of-arrival results are affected by the elastic wave velocity in rock sample. Lei et al. (2004) investigated the spatial distribution of the $\mathrm{AE}$ events during the failure process of jointed rock mass under triaxial compression: $\mathrm{AE}$ activity is modeled quantitatively in terms of the seismic b-value of the magnitude-frequency relation, the self-excitation strength of the AE time series, and the fractal dimension of $\mathrm{AE}$ hypocenters. Consistent with previous studies on rock samples containing a fracture plane with several asperities, the present analyses reveal three long-term phases of $\mathrm{AE}$ activity associated with damage creation on heterogeneous faults, each clearly identifiable based on the above parameters. Zuo et al. (2011) used a real time AE events three-dimensional positioning apparatus studied the $\mathrm{AE}$ characteristics and their spatio-temporal evolution mechanism for coal, rock, and coal and rock combination: The experimental results indicate that with the increase of load, the cumulative AE numbers of single rock, single coal and coal-rock combined bodies are increasing. With the increase of load, the AE number in a time interval gradually increases in rock, decreases in coal, and increases initially and then decreases in coal-rock combined body. Tang and Xu (1990) established the rock material failure model under uniaxial compression by using the continuum damage mechanics theory: It is proved that the acoustic emission count $\mathrm{N}$ shows no difference with damage parameter $\mathrm{D}$. The acoustic emission count $\mathrm{N}$ is therefore used to describe the constitutive relation of the rock. The theoretical result agress quite well with that from experiments.

Rock similar materials can simulate the complex implementation process and condition in geotechnical engineering and overcomes the challenges in field measurement. Similar material simulation experimental studies have been widely used in the field of mining, tunneling, and water conservancy. Therefore, there is a need for the systematical study of the deformation failure characteristics for rock similar material with pre-existing cracks. In the study of the AE evolution characteristics, there are few studies on the influence of fracture parameters on the evolution of AE events. Further study is needed due to that the crack parameters have great impact on the AE evolution characteristics.

Based on the above analysis of the research status, in this study, the influence of crack length to the deformation and failure mode, $\mathrm{AE}$ events and micro cracks development, and damage properties of rock similar materials are investigated. The outcomes provide basis for the research of instability failure and crack development mechanism of geotechnical engineering similar material models.

\section{Experimental designs}

\subsection{Preparation of rock similar material specimens}

Similar materials consist of sand (aggregate), cement (cementing agent), gypsum (cementing agent) and starch (cementing agent). The sand to cement weight ratio is 10:1. The completed samples $(\Phi 50 \mathrm{~mm} \times 100 \mathrm{~mm})$ are shown in Fig. 1. One typical group of specimens is presented in 


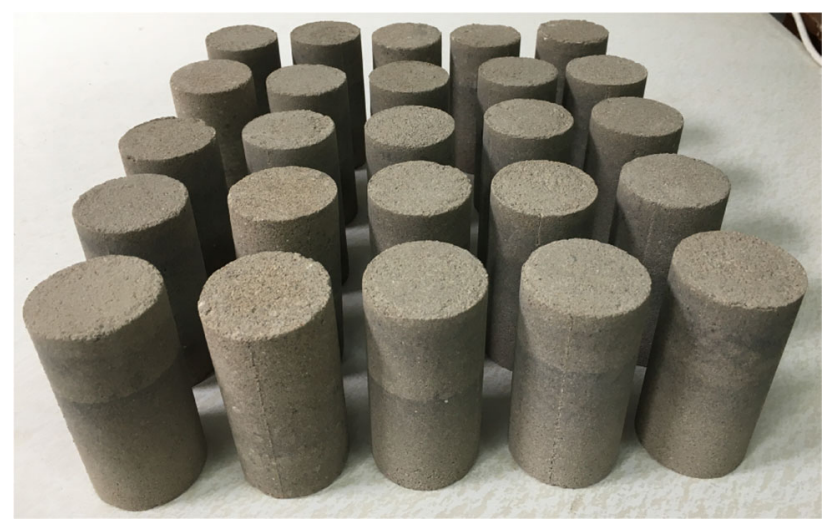

Fig. 1 The prepared rock similar material specimens

this paper. The three specimens in this group are numbered L-1, L-2, and L-3. The crack length for specimen L-1, L-2, and $\mathrm{L}-3$ are 30,40 , and $50 \mathrm{~mm}$, respectively. The width of the cracks is $3 \mathrm{~mm}$, and the angle is $45^{\circ}$ (Fig. 2).

\subsection{Loading conditions and damage monitoring design}

Self-developed YYW-II uniaxial compression tester (Fig. 3) is used for loading equipment. The loading rate is $0.87 \mathrm{~mm} / \mathrm{min}$. The PCIE- $8 \mathrm{AE}$ system is used for damage monitoring. The system can use the AE signal for three dimensions space localization. The threshold value is set to be $40 \mathrm{~dB}$, the transmission gain for the preamplifier is $40 \mathrm{~dB}$, the sampling frequency is $10 \mathrm{MHz}$, and the resonant frequency for the sensor is $1-100 \mathrm{kHz}$.

Six sensor array was used to collect the AE signals (Fig. 3). The six sensors are arranged to the top, middle, and bottom layer of the specimen, and each layer uses two sensors. The sensors on one layer were aligned perpendicular to the layer next to it for improved accuracy. Thin slices of polytetrafluoroethylene are placed on the two ends

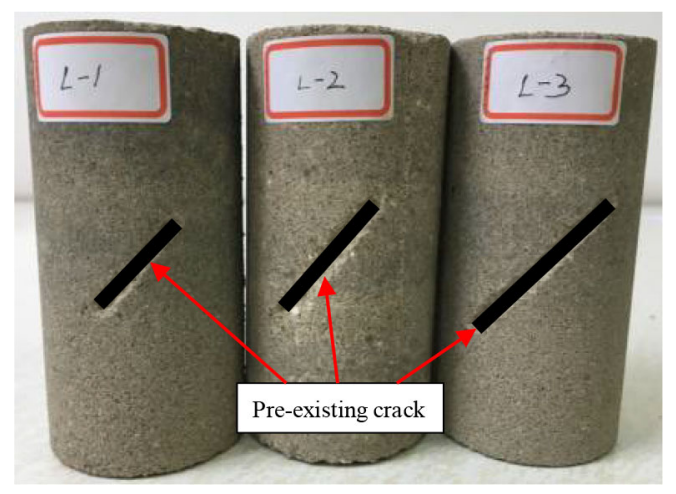

Fig. 2 Prepared specimens with different length of pre-existing cracks

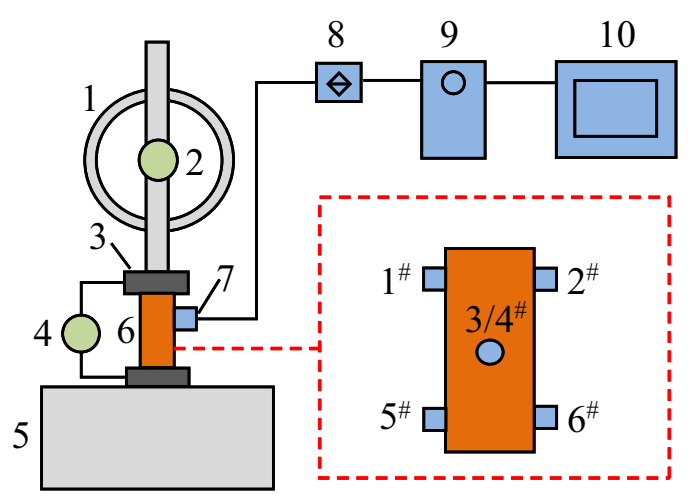

Fig. 3 Loading and testing system

of the specimen to reduce the restraining effect of the end friction.

\subsection{Experiment procedure}

Figure 4 shows the experiment procedure. According to the experimental design, six acoustic emission sensors are fixed firmly on the sample according to the designed position, placed on the loading platform, connected to the acoustic emission monitoring system, and system parameters are set. The samples were loaded according to the designed loading speed, and the stress, strain, failure, acoustic emission and other parameters in the loading process were recorded. After the completion of the experiment, the samples were taken out, and the final failure forms of the samples were recorded. The strength and deformation characteristics, failure mode and feature, damage space development process, AE events and energy activity characteristics, as well as the damage stage variation characteristics were comprehensively analyzed during the loading process. Then come to the final conclusion.

\section{Mechanical properties and failure characteristics}

\subsection{Strength and deformation characteristics}

Figure 5 shows the stress-strain curve for specimen L-1, L-2, and L-3 during the entire uniaxial compression test. As can be seen, they all have four stages: initial compression (from $\mathrm{O}$ to $\mathrm{A}$ ), elastic deformation (from $\mathrm{A}$ to $\mathrm{B}$ ), plastic deformation (from $\mathrm{B}$ to $\mathrm{C}$ ), and failure (from $\mathrm{C}$ to D). In the initial stage, the original damage and micro pores in the specimen are closed causing the increase of strain and bearing capacity, and thus the stress increases. With the increase of loading, the specimen exerts elastic deformation when the stress increases linearly with the strain. Damages are generated steadily in the inside of the 


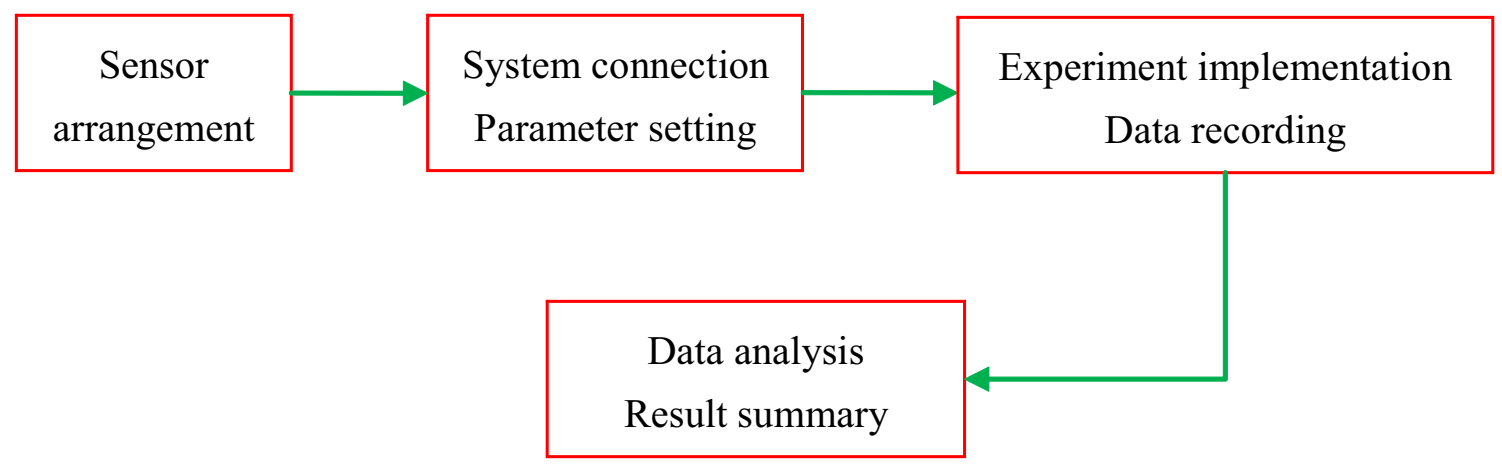

Fig. 4 Experiment procedure

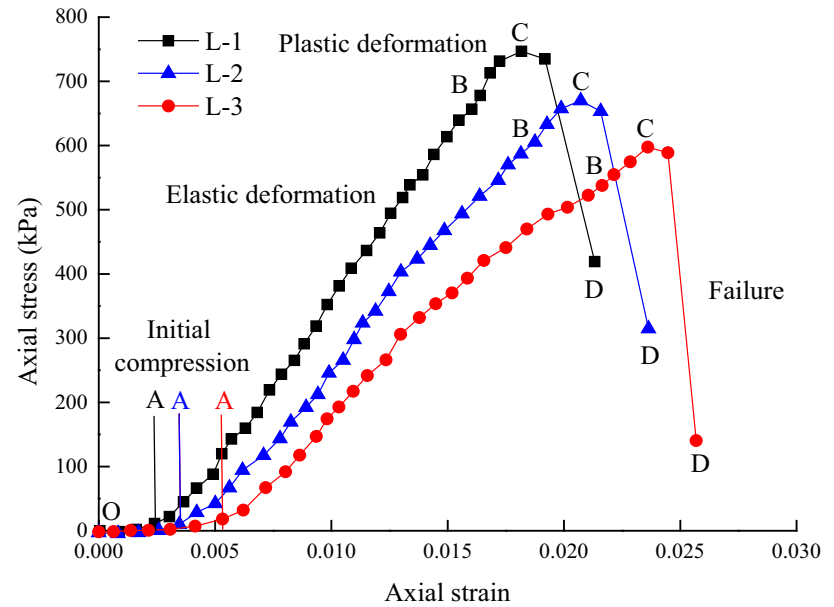

Fig. 5 The stress-strain curves

specimen. When the loading approaches the peak load, the specimen enters the plastic deformation stage and the stress-strain linear relationship does not maintain. The damage in the specimen are generated and connected in a rapid manner, which forms the main failure plane. Failure occurs when the load increases to the peak stress that causes the connection of cracks in the main failure plane. After this, stress reduces rapidly to its residual stress. Based on the above analysis, the overall trend of the stressstrain for specimen L-1, L-2, and L-3 are similar, thus the length of the pre-existing cracks have no apparent influence on their deformation.

For specimen L-1, L-2, and L-3, the peak strength are $746.84,669.915$, and $597.643 \mathrm{kPa}$, respectively, and the residual strength are $199.117,164.761$, and $110.375 \mathrm{kPa}$, respectively. These indicate the peak strength and residual strength are related to the length of the pre-existing cracks. The length of the pre-existing cracks represents the level of initial damage to the specimens, with longer cracks represent more initial damage. Therefore, as shown in Fig. 6, both the peak strength and residual strength reduce with the increase of the pre-existing crack length. Also, as summarized in Fig. 7, the peak axial strain and the strain during

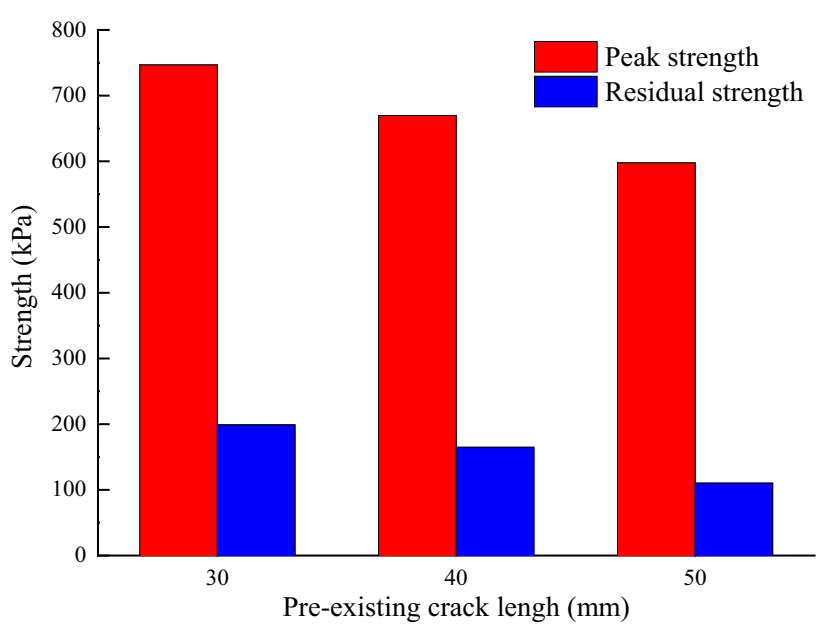

Fig. 6 The change of the peak strength and residual strength

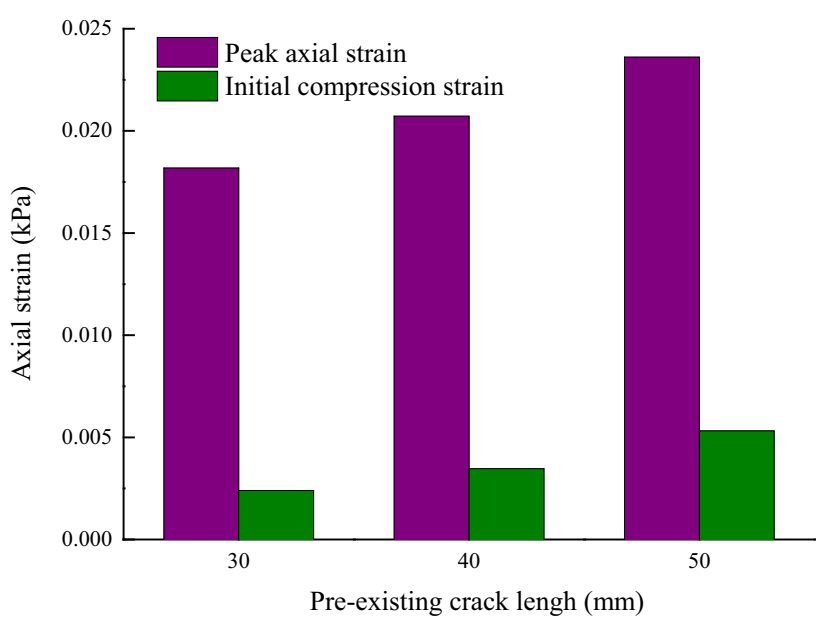

Fig. 7 The change of the peak axial strain and initial compression strain

the compression phase for the three specimens are 0.01818 , $0.02072,0.02361$, and $0.0024,0.00347$, and 0.00532, respectively. Both of them increase with the increase of pre-existing crack length. 


\subsection{Failure mode and feature}

Figure 8 shows the failure modes for the three tested specimens. For specimen L-1 (Fig. 8a), when the crack length is $30 \mathrm{~mm}$, a major vertical crack was formed after failure which cut-through the specimen. Shear failure occurred which was dominated by its material properties, whereas the pre-existing crack had little impact to the failure. At this point, during the compression process, the axial compressive stress of the sample increases continuously, and the shear stress concentration gradually appears at the original weak surface inside the sample, resulting in the shear micro-failure and gradual accumulation. When the compressive stress reaches the peak strength, the weak surface inside the sample produces shear slip, and the sample suffers shear failure.

For specimen L-2 (Fig. 8b), when the crack length is $40 \mathrm{~mm}$, a major failure occurred in the middle of the specimen where the crack was located, and a major crack was formed through the middle to the bottom part of the specimen. Shear failure was dominated, but some tensile failure occurred. It indicates that the prefabricated crack has a certain influence to the damage of specimen, in the process of sample compression, due to influence of the prefabricated crack, some tension stress formed in the region of the prefabricated crack. Under the action of the composite stress of shear and tension, when the peak strength is reached, the middle part of the sample forms shear failure and large area tensile failure.

For specimen L-3 (Fig. 8c), when the crack length is $50 \mathrm{~mm}$, a major vertical crack was formed after failure which cut-through the middle of the pre-existing crack. The formed crack started from the top to the bottom of the specimen. These indicated that, during compression, to the influence of the prefabricated crack, the concentrated tensile stress formed in the middle of prefabricated crack, the specimen first produced local tensile failure, and then,

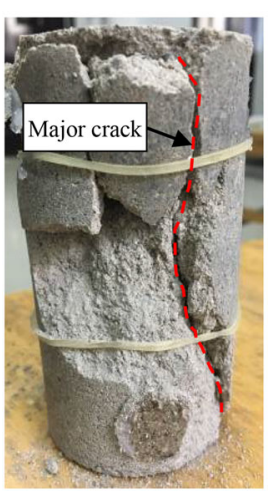

(a) L-1

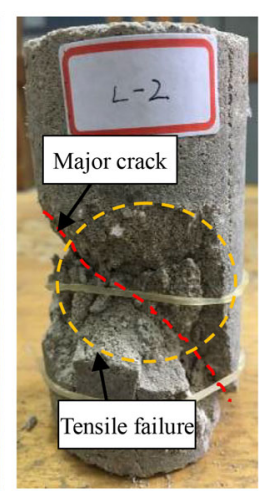

(b) L-2

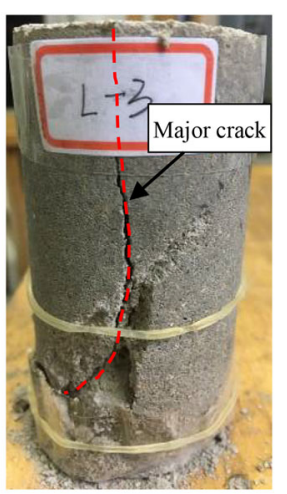

(c) L-3
Fig. 8 Failure mode for specimens with different pre-existing crack under the action of continuous compressive stress, the secondary weak surface formed by tensile failure produced tensile failure that continuously developed to the top and bottom of the specimen. When the compressive stress reached the peak strength, the specimen underwent tensile main failure.

By comparing the results of the three specimens, the effect of the length of the pre-existing crack to the failure mode increases with the increase of the pre-existing crack length. The dominate failure mode changes from shear failure to longitudinal tensile failure that cut-through the middle of the created crack.

\section{Law of damage space development during loading process}

\subsection{Damage space development process for specimen $\mathrm{L}-1$}

The AE events localization results for specimen L-1 can be seen in Fig. 8. The AE events spatial evolution process can reflect characteristics for the mechanical deformation of the specimen. The process can be classified into the following three phases.

As shown in Fig. 9a, in the process of increasing the load to about $2 \%$ of the peak stress, initially only few scattered AE events appears near the bottom of the specimen. And later the number of AE events and the area of coverage increases. This indicates that some micro damage caused damage starts to develop near the specimen bottom. This phase is in correspondence to the initial compression stage OA in Fig. 5.

As can be seen from Fig. 9b-e, when sample continue loading to $93 \%$ of the peak stress, the $\mathrm{AE}$ events and its coverage area further develop and form AE events clusters. $\mathrm{A}$ number of $\mathrm{AE}$ events also occur and develop in the middle and top part of the specimen. These represent the increase and development of damage and formation of damage zone at the bottom part; micro damage starts to happen in the middle and top part of the specimen causing some damage. This phase is in correspondence to the elastic deformation stage $\mathrm{AB}$ in Fig. 5.

Figure 9f shows the AE events activities when the load is increased to the peak stress. The number of AE events rapidly increase in the middle and top part. The $\mathrm{AE}$ events develop toward the top of the specimen and the AE events clusters in the bottom part, and connect them and form $\mathrm{AE}$ events zone. In this process, the micro damage increase rapidly in the middle and top part and formed many damage. A major damage crack plane is formed when the damage are connected through the top surface to the bottom surface. This phase is in correspondence to the plastic 


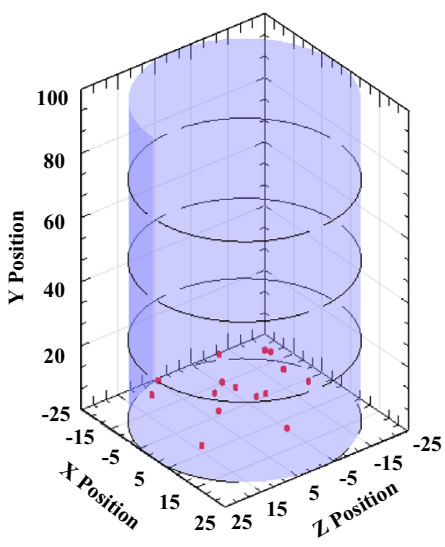

(a) $2 \%$ peak stress

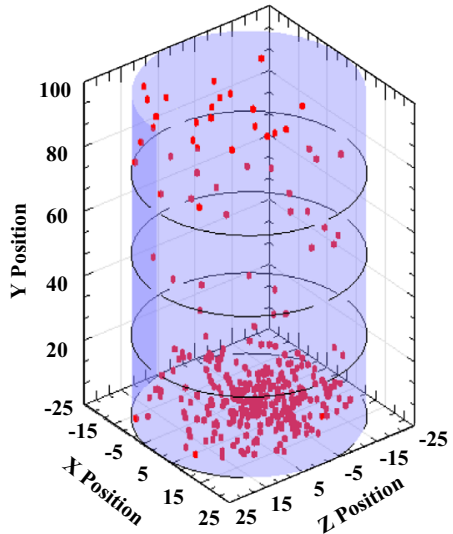

(d) $81 \%$ peak stress

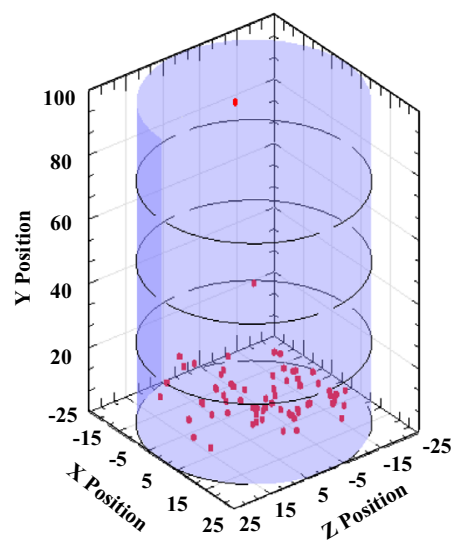

(b) $30 \%$ peak stress

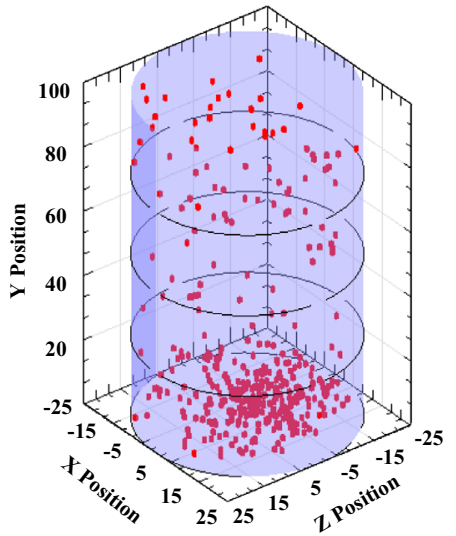

(e) $93 \%$ peak stress

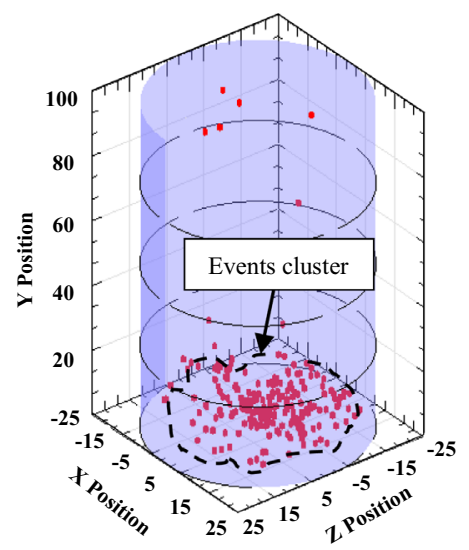

(c) $60 \%$ peak stress

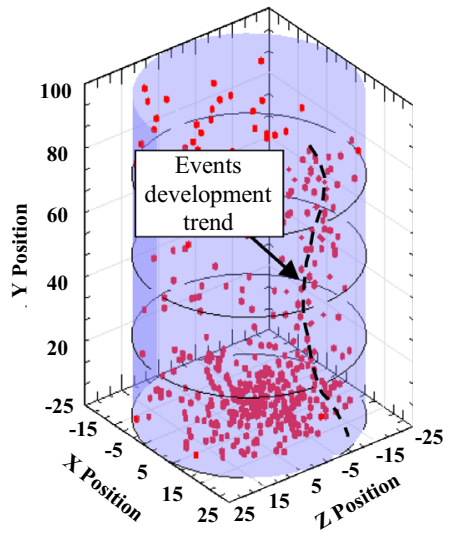

(f) $100 \%$ peak stress

Fig. 9 AE events localization results for specimen L-1

deformation stage $\mathrm{BC}$ and failure stage $\mathrm{CD}$ in Fig. 5. The $\mathrm{AE}$ events clustered and connected plane is in highly match to the failure plane shown in Fig. 8a, indicating a high precision and accuracy of the $\mathrm{AE}$ events localization technique.

As the AE events spatial distribution does not have clear relationship to the location of the pre-existing crack, this means a $30 \mathrm{~mm}$ pre-existing crack only has minimum effect to the development of the damage in the loading process.

\subsection{Damage space development process for specimen $\mathrm{L}-2$}

The AE events localization results for specimen L-2 can be seen in Fig. 10. Similar to that of specimen L-1, the AE events spatial evolution process can also reflect characteristics for the mechanical deformation of the specimen. Three phases are also classified.

As shown in Fig. 10a, in the process of increasing the load to about $3 \%$ of the peak stress, AE events are firstly appeared at the top part of the specimen, and few scattered AE events are also appeared at the middle and the bottom parts. These show that the micro damages are initiated from the top part, and only few micro damages occur in the middle and bottom parts. This phase is in correspondence to the initial compression stage OA in Fig. 5.

In the process of continuing to load the specimen up to $90 \%$ of the peak stress, AE events start to increase near the location where the pre-existing crack is located, and more $\mathrm{AE}$ events are also generated at the bottom part and form AE events cluster, as shown in Fig. 10b-e. These indicate that the micro damages are gradually increased in the preexisting crack area, and the pre-existing crack starts to influence the generation and development of the damage. More micro damages start to accumulate at the bottom part and forms several concentrated micro crack area. This phase is in correspondence to the elastic deformation stage $\mathrm{AB}$ in Fig. 5.

As shown in Fig. 10f, when the specimen is further loaded to the peak stress, there is a rapid increase in the number of $\mathrm{AE}$ events around the pre-existing crack area and $\mathrm{AE}$ events clusters are formed. These $\mathrm{AE}$ events quickly extend to the bottom and connect with the bottom $\mathrm{AE}$ events cluster. It means more micro damages are formed in the pre-existing crack area, and the formed micro crack develop toward the bottom part and connect with the 


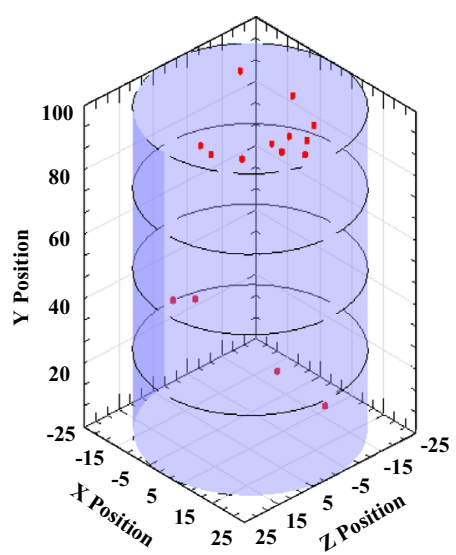

(a) 3\% peak stress

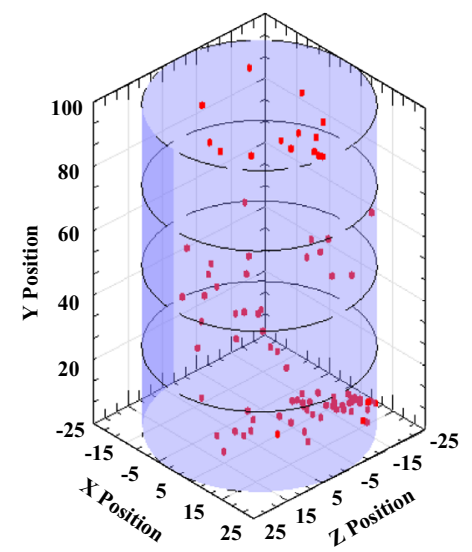

(d) $78 \%$ peak stress

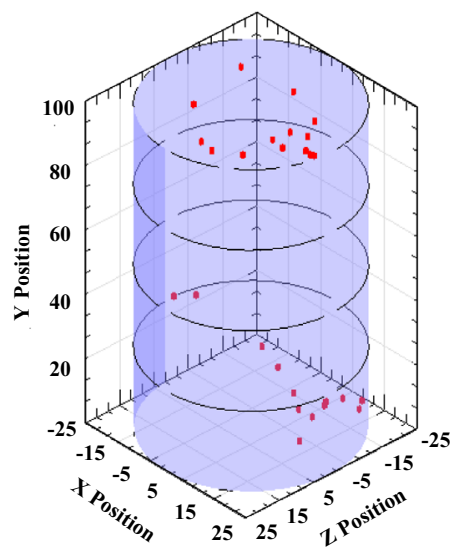

(b) $29 \%$ peak stress

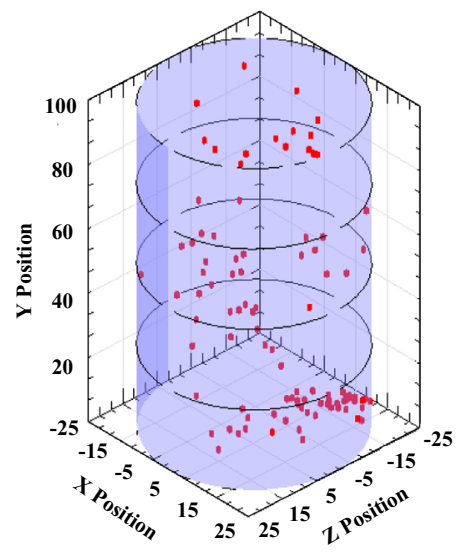

(e) $90 \%$ peak stress

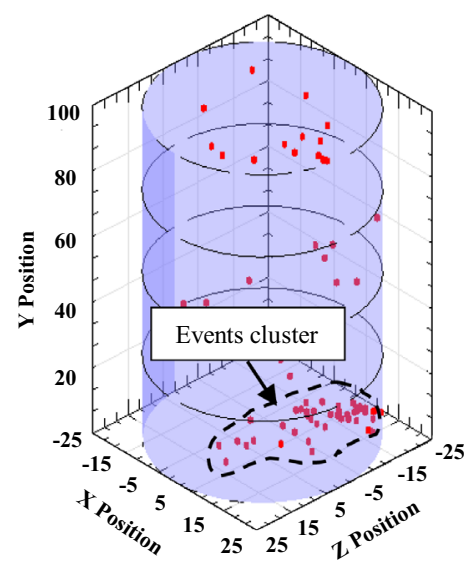

(c) $68 \%$ peak stress

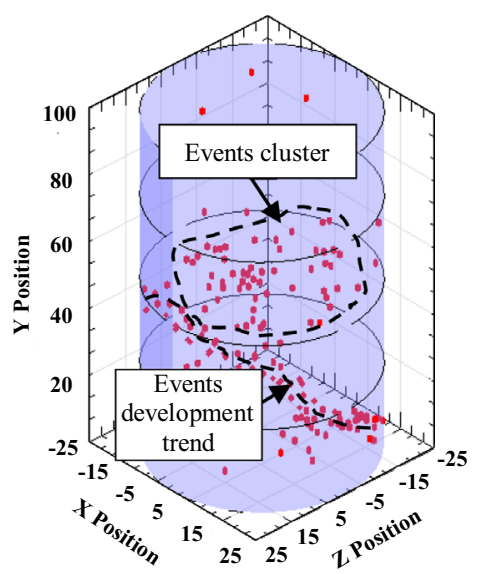

(f) $100 \%$ peak stress

Fig. 10 AE events localization results for specimen L-2

bottom micro crack zone. The pre-existing crack shows more impact to the damage generation and development, and a major damage plane is formed from the middle of the specimen to the bottom, which causes a main fracture. This phase is in correspondence to the plastic deformation stage $\mathrm{BC}$ and failure stage $\mathrm{CD}$ in Fig. 5. The AE events clustered and connected plane is in highly match to the failure plane shown in Fig. 8b.

The above analysis shows that a $40 \mathrm{~mm}$ pre-existing crack influence the generation and development of the damage, and the tensile force created near the pre-existing crack location causes micro damages and the development of the damage.

\subsection{Damage space development process for specimen $L-3$}

The AE events localization results for specimen L-3 are shown in Fig. 11. Similar to the analysis for specimen L-1 and L-2, three phases are also identified and they are discussed in detail below.

In the first phase, the specimen is loaded to $5 \%$ of the peak stress. As shown in Fig. 11a, several AE events are generated at the bottom part that indicates the occurrence of some micro damages. This phase is in correspondence to the initial compression stage OA in Fig. 5.

In the second phase, the specimen is continued to load up to $92 \%$ of the peak stress. As demonstrated in Fig. 11be, more AE events gradually occur at the bottom and form $\mathrm{AE}$ events cluster. Some AE events are generated in the top parts. Increased AE events occur in the middle where the pre-existing crack is made, and they are extending toward the top and bottom parts. In this phase, more micro damages are generated at the bottom part and micro crack zones are formed. Some micro damages start to develop at the top part. Due to the existence and effects of the preexisting crack, relatively larger tensile force is generated near the pre-existing crack, which causes the development 


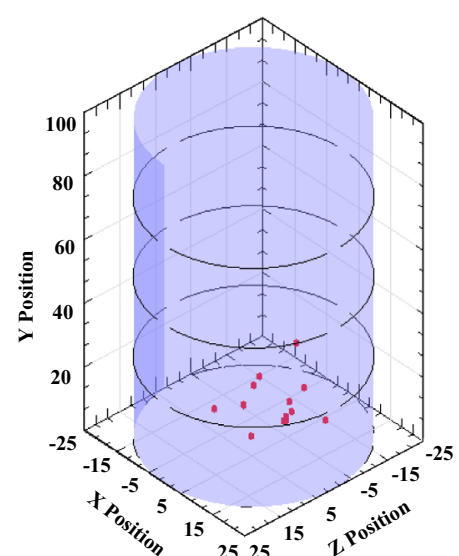

(a) $5 \%$ peak stress

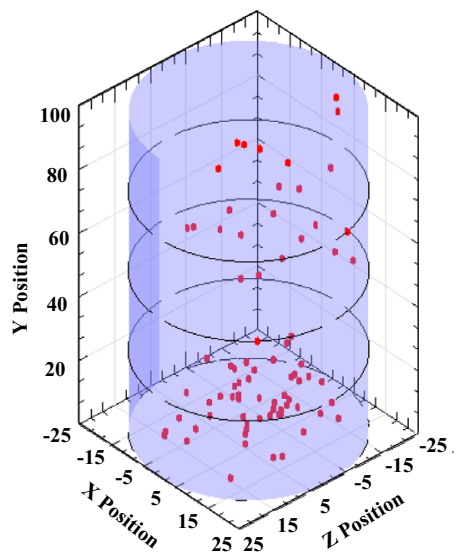

(d) $80 \%$ peak stress

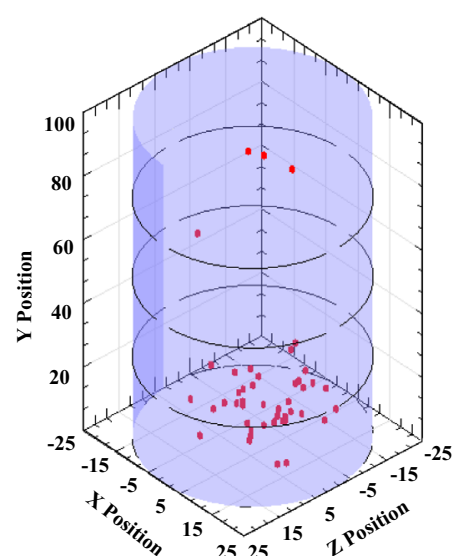

(b) $30 \%$ peak stress

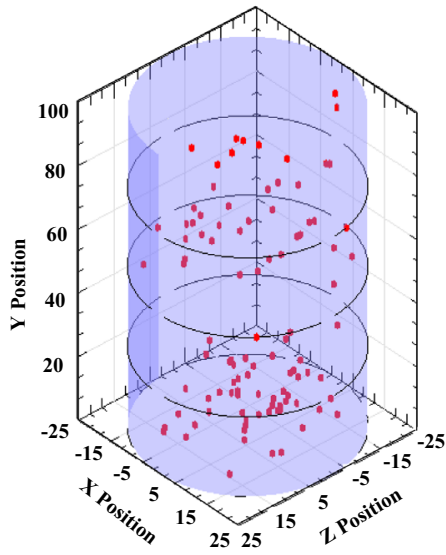

(e) $92 \%$ peak stress

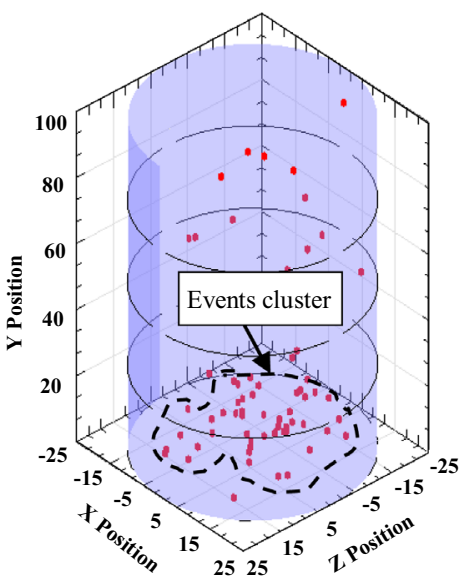

(c) $70 \%$ peak stress

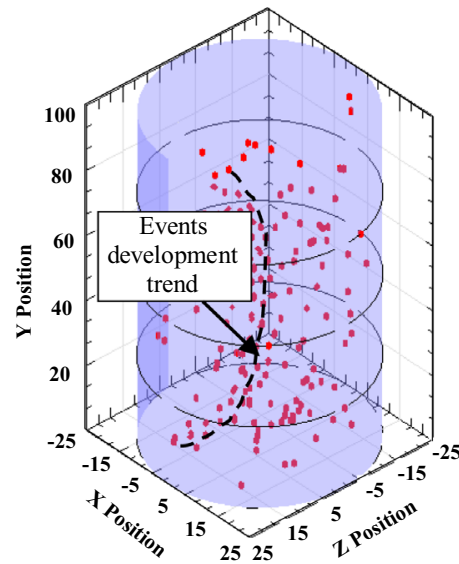

(f) $100 \%$ peak stress

Fig. 11 AE events localization results for specimen L-3

of micro damages in this area and their extension to the top and bottom parts. This phase is in correspondence to the elastic deformation stage $\mathrm{AB}$ in Fig. 5.

In third phase, specimen is loaded to peak stress. As depicted in Fig. 11f, rapid increase of AE events occurs in the middle part. An AE events cluster is formed which passes from the top though the middle of the pre-existing crack to the bottom part of the specimen. This is the cause of the failure. This phase is in correspondence to the plastic deformation stage $\mathrm{BC}$ and failure stage $\mathrm{CD}$ in Fig. 5. The $\mathrm{AE}$ events clustered and connected plane is in highly match to the failure plane shown in Fig. 8c.

The analysis above shows that a $50 \mathrm{~mm}$ pre-existing crack has played a leading role in the generation and development of damage. It causes tensile stress concentration in the middle of the pre-existing crack, which causes the generation of damage and their further extension to the top and middle part of the specimen. This finally leads to the form of a vertical main fracture through the middle of the pre-existing crack.

Over all, based on the analysis of the development of damage for specimen L-1, L-2, and L-3, the effects of the pre-existing cracks increase with their length increase from 30 to $50 \mathrm{~mm}$. The leading role of the tensile failure near the pre-existing crack area becomes more apparent with the increase of the pre-existing crack length.

\section{Damage evolution characteristics during loading process}

\subsection{AE events and energy activity characteristics}

Figure 12 shows the accumulative AE events and energy during the uniaxial compression tests for specimen L-1, L-2, and L-3. As can be seen, the accumulative AE events 


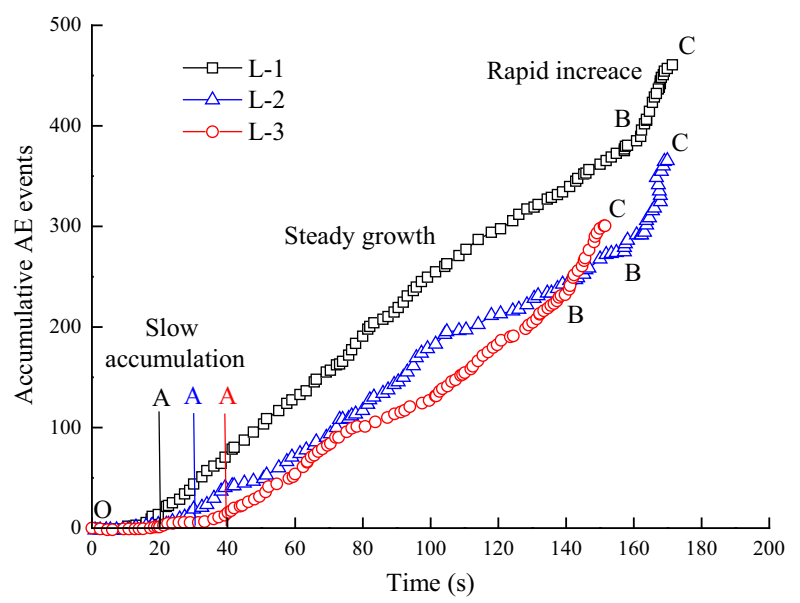

(a) Accumulative $\mathrm{AE}$ events

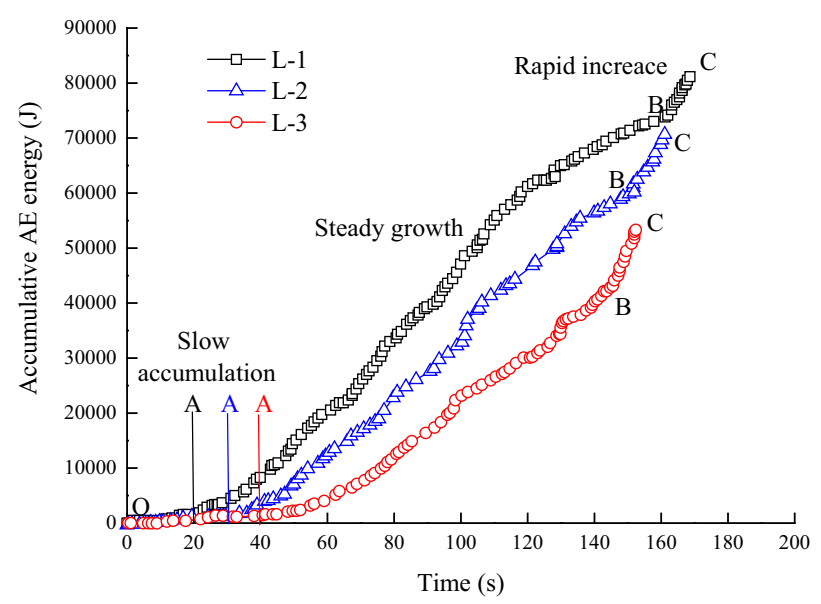

(b) Accumulative AE energy

Fig. 12 AE activities for specimen L-1 to L-3

and energy are closely related with similar curve trend. The curves can be divided into three stages: slow accumulation in stage $\mathrm{OA}$, steady growth of $\mathrm{AE}$ events in stage $\mathrm{AB}$, and rapid increase of $\mathrm{AE}$ events in stage $\mathrm{BC}$. The three stages can be closely related to specimens' deformation process. There are less AE events in the initial compression stage, and thus the accumulative energy is less. With increased loading, when specimen deformation is in the elastic deformation stage, AE events and accumulative energy increase steadily. After that, plastic deformation occurs to the specimen with rapidly increase of $\mathrm{AE}$ events and accumulative energy.

Comparing the curves for different specimens, there is little difference in the initial compression stage OA, but obvious discrepancies occurs in stage $\mathrm{AB}$ and $\mathrm{BC}$. In stage $\mathrm{AB}$, for the three specimens, the accumulative $\mathrm{AE}$ events and energy are 382, 271, 255, and $75761 \mathrm{~J}, 60804 \mathrm{~J}$, $41452 \mathrm{~J}$, respectively. And In stage BC, they are 465, 379, 306, and $82278 \mathrm{~J}, 70482 \mathrm{~J}, 54152 \mathrm{~J}$, respectively. It means both the accumulative AE events and energy reduces with the increase of the length of pre-existing cracks.

\subsection{Damage stage variation characteristics}

$\mathrm{Li}$ et al. (2017) used the accumulative $\mathrm{AE}$ events as the characteristic parameter, and established the damage model based on accumulative AE events for rock similar materials under uniaxial compression, and then proved the rationality of the damage model.

$\sigma=E \varepsilon(1-D)=E \varepsilon\left(1-\left(1-\frac{\sigma_{c}}{\sigma_{p}}\right) \frac{N_{d}}{N_{m}}\right)$

where $\sigma$ is the actual uniaxial stress; $D$ is damage variable; $E$ is modulus of elasticity; $\varepsilon$ is the strain; $N_{m}$ is the number of accumulative $\mathrm{AE}$ events when material failure; $N_{d}$ is the accumulative $\mathrm{AE}$ events generated; $\sigma_{p}$ is the peak stress; and $\sigma_{c}$ is the residual strength.

Based on the experimental results and the failure model, the parameters for specimen L-1 are $\sigma_{p}=746.84 \mathrm{kPa}$, $\sigma_{c}=199.117 \mathrm{kPa}, E=41000 \mathrm{kPa}, N_{m}=465$, for L-2 are $\sigma_{p}=669.915 \mathrm{kPa}, \quad \sigma_{c}=164.761 \mathrm{kPa}, \quad E=32331 \mathrm{kPa}$, $N_{m}=379$, and for L-3 are $\sigma_{p}=597.643 \mathrm{kPa}, \sigma_{c}=-$ $110.375 \mathrm{kPa}, E=25313 \mathrm{kPa}, N_{m}=306$. The damagestrain curve is shown in Fig. 13. The theoretical and experimental stress-strain curves have very similar trends (Fig. 14), The test stress-strain curve is basically located below the theoretical stress-strain curve. It is because there is a stress loss in the process of the test, and the measured stress is slightly less than the theoretical calculation.

Similar to previous analysis, the damage development process can be divided into three stages: initial damage stage (OA), damage stable development stage (AB), and damage rapid development stage $(\mathrm{BC})$. The damage variables for the three specimens in the initial damage stage are similar, meaning minimum influence of the pre-existing crack to specimens' damages in this stage. The maximum damage variables for L-1, L-2, and L-3 in the damage stable development stage are 0.621, 0.633, and 0.655, respectively, so the maximum difference is 0.017 . And they are $0.734,0.775$, and 0.817 in the damage rapid development stage, with a maximum difference of 0.042 . This means a longer pre-existing crack length increases the damage variable in the damage stable development stage and the rapid development stage. And such effect is more obvious in the rapid development stage.

Based on polynomial curves fitting of the curves in Fig. 13, the damage evolution equations are obtained as Eqs. (2)-(4). The degree of fitting is between 0.97287 and 0.99783 , indicating a preferable fitting result. 


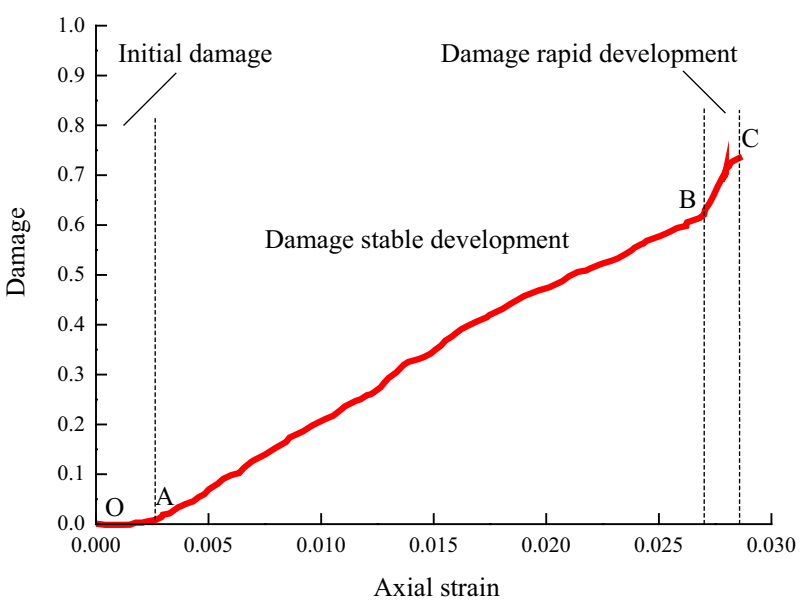

(a) L-1

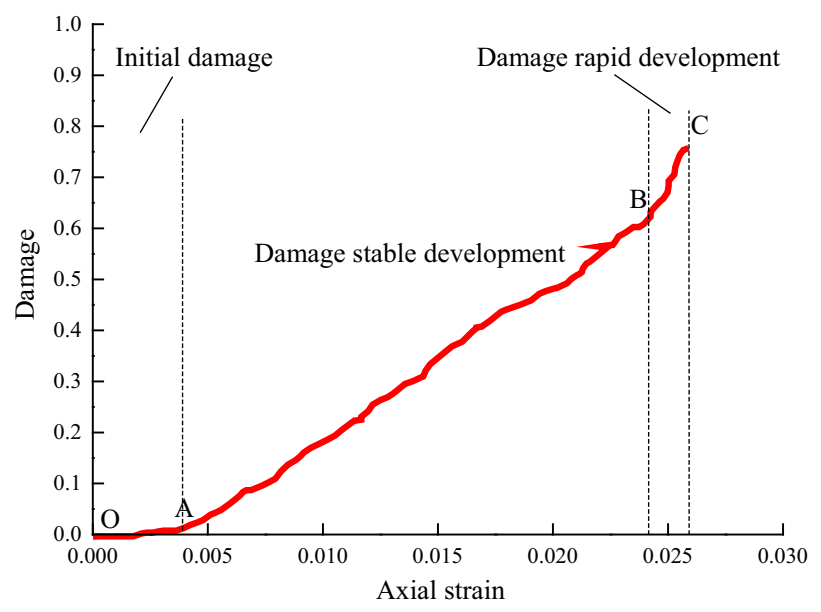

(b) L-2

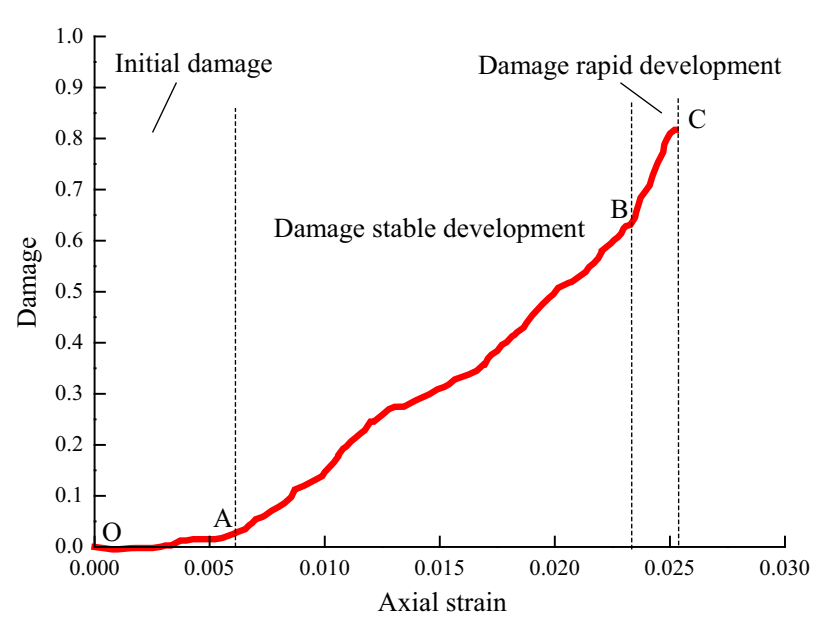

(c) L-3

Fig. 13 The damage-strain curves

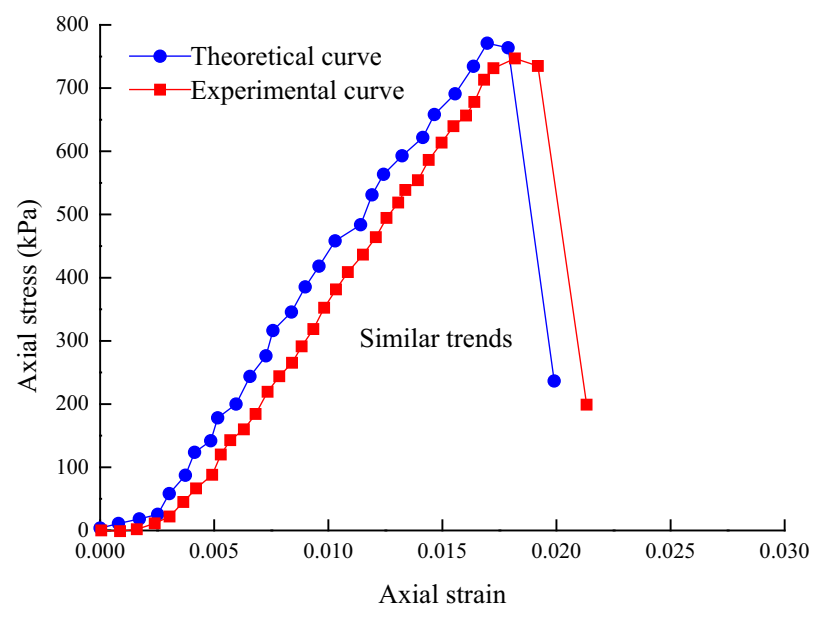

(a) L-1

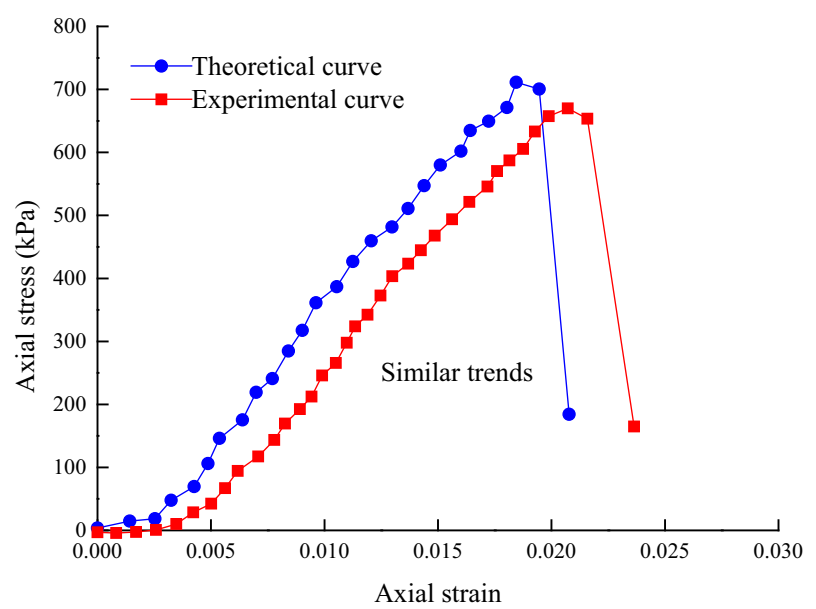

(b) L-2

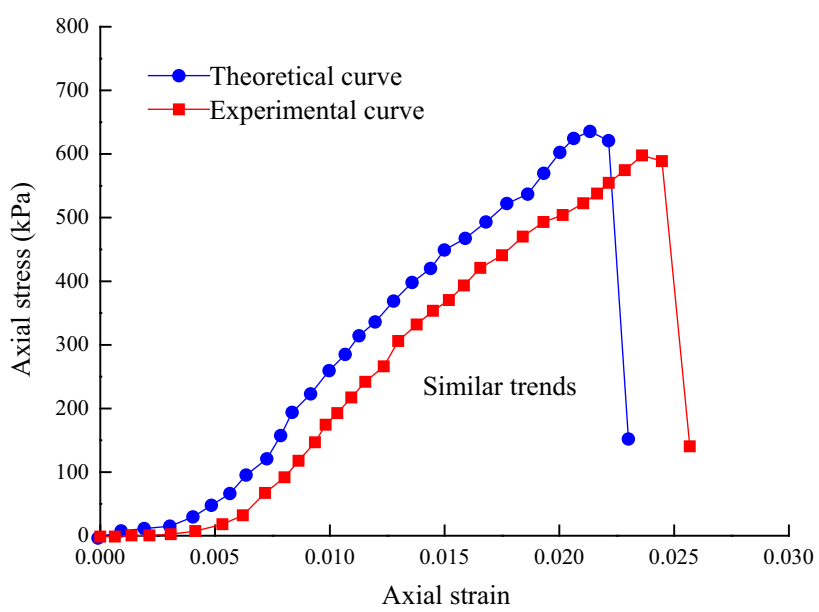

(c) L-3

Fig. 14 Comparison of theoretical and experimental stress-strain curves 
L-1 : $\quad D=\left\{\begin{array}{r}1.16707 \times 10^{-4} \varepsilon^{2}-0.00126 \varepsilon+0.00141(0 \leq \varepsilon \leq 0.0025) \\ -6.97826 \times 10^{-6} \varepsilon^{2}+0.00552 \varepsilon-0.09286(0.0025 \leq \varepsilon \leq 0.0271) \\ -5.27048 \times 10^{-4} \varepsilon^{2}+0.18848 \varepsilon-16.08236(0.0271 \leq \varepsilon \leq 0.0292)\end{array}\right.$
L-2 : $\quad D=\left\{\begin{array}{r}4.25156 \times 10^{-5} \varepsilon^{2}-2.42082 \times 10^{-4} \varepsilon+0.00347(0 \leq \varepsilon \leq 0.0045) \\ -9.08661 \times 10^{-7} \varepsilon^{2}+0.00526 \varepsilon-0.12773(0.0045 \leq \varepsilon \leq 0.0238) \\ 6.29261 \times 10^{-4} \varepsilon^{2}-0.17367 \varepsilon+12.57488(0.0238 \leq \varepsilon \leq 0.0263)\end{array}\right.$
L-3 : $\quad D=\left\{\begin{array}{r}2.56533 \times 10^{-5} \varepsilon^{2}-1.10943 \varepsilon-0.00334(0 \leq \varepsilon \leq 0.0061) \\ 7.95324 \times 10^{-6} \varepsilon^{2}+0.00428 \varepsilon-0.13486(0.0061 \leq \varepsilon \leq 0.0232) \\ -1.57256 \times 10^{-4} \varepsilon^{2}+0.06228 \varepsilon-5.00218(0.0232 \leq \varepsilon \leq 0.0265)\end{array}\right.$

Further derive the above equations according to Eq. (1), we can get the damage constitutive equations for the three tested specimens. which highly influence the mechanical properties and failure modes if they are used for experiments.

L-1 $: \quad \sigma=41000 \varepsilon\left[\begin{array}{r}-1.16707 \times 10^{-4} \varepsilon^{2}+0.00126 \varepsilon+0.99859(0 \leq \varepsilon \leq 0.0025) \\ 6.97826 \times 10^{-6} \varepsilon^{2}-0.00552 \varepsilon+1.09286(0.0025 \leq \varepsilon \leq 0.0271) \\ 5.27048 \times 10^{-4} \varepsilon^{2}-0.18848 \varepsilon+17.08236(0.0271 \leq \varepsilon \leq 0.0292)\end{array}\right]$
L-2 $\quad \sigma=32331 \varepsilon\left[\begin{array}{r}-4.25156 \times 10^{-5} \varepsilon^{2}+2.42082 \times 10^{-4} \varepsilon+0.99653(0 \leq \varepsilon \leq 0.0045) \\ 9.08661 \times 10^{-7} \varepsilon^{2}-0.00526 \varepsilon+1.12773(0.0045 \leq \varepsilon \leq 0.0238) \\ -6.29261 \times 10^{-4} \varepsilon^{2}+0.17367 \varepsilon-11.57488(0.0238 \leq \varepsilon \leq 0.0263)\end{array}\right]$
L-3 : $\sigma=25313 \varepsilon\left[\begin{array}{r}-2.56533 \times 10^{-5} \varepsilon^{2}+1.10943 \varepsilon+1.00334(0 \leq \varepsilon \leq 0.0061) \\ -7.95324 \times 10^{-6} \varepsilon^{2}-0.00428 \varepsilon+1.13486(0.0061 \leq \varepsilon \leq 0.0232) \\ 1.57256 \times 10^{-4} \varepsilon^{2}-0.06228 \varepsilon+6.00218(0.0232 \leq \varepsilon \leq 0.0265)\end{array}\right]$

\section{Discussions}

The purpose of this study for using rock similar materials is that most of the current similar material model experimental researches in the field of geotechnical engineering only focus on the macroscopic phenomena and its data analysis, and there is a need for the investigation from the micro perspective. A deeper level of understanding from the mechanism aspect is lacking, which causes that the research findings cannot be applied to the geotechnical engineering practice accurately and reliably. In addition, nature rocks have pre-existing and secondary fractures,
To overcome the above mentioned shortages, this paper studied the deformation, damage evolution, and damage characteristics for rock similar materials with pre-existing cracks. The length of the pre-existing crack is set as the variable, and its influences to the damage of the rock similar materials are investigated. Pre-existing crack has other parameters, such as the width, the depth, and the angle, which may also has impact to rock failure. These need to be included in future studies to reveal the in-depth mechanism for the failure of rock similar materials and provide strong reference for the similar material simulation experimental research of geotechnical engineering. 
Most of the previous studies focused on the influence of the crack parameters to the mechanical properties and failure modes of rock. Few researches have studied its influence to the rock failure evolution. This paper studied the influence of pre-existing crack length to the compaction failure process, AE events activities, and damage developments, established the inoculation, generation, and development for the damage of rock similar materials, and improved the understanding of damage evolution mechanism for rock similar materials with pre-existing cracks.

Past researches investigate the rock damage properties based on $\mathrm{AE}$ ringing counts. However, compared to $\mathrm{AE}$ ringing counts, the number of $\mathrm{AE}$ events can reflect the local change of material more directly. This paper uses the accumulative $\mathrm{AE}$ events as the characteristic parameter, and established the damage model for rock similar materials under compression. Based on this, the influences of pre-existing crack to the damage characteristics are investigated. The established damage model accurately described the damage evolution for the tested material, and further revealed its damage characteristics.

The findings of this paper further revealed the damage mechanism for rock similar materials, and provided reference basis for the study of instability failure characteristics and crack evolution mechanisms of similar material simulation in geotechnical engineering.

\section{Conclusions}

This study conducted uniaxial compression for rock similar materials with different length of pre-existing cracks. The influence of the length of pre-existing cracks to specimens' damage and failure characteristics are investigated. Findings are summarized in the following.

(1) The peak strength and residual strength decreases with the increase of pre-existing crack length, but the peak axial strain and the strain during the initial compression stage increases. The influence to the failure mode increases with increased pre-existing crack length. The dominant failure mode changes from shear failure to tensile failure with the failure plane cut through the middle of the pre-existing crack.

(2) With the increase of the length of the pre-existing crack, its influence to the damage space development increases, and the tensile force in the pre-existing crack area shows enhanced effect to the development of damage.

(3) With the length increase of the pre-existing cracks, the accumulative $\mathrm{AE}$ events and energies reduces, indicating weakened $\mathrm{AE}$ events activities. The initial damage for the three types of specimens are similar, but the influence increases in the damage stable and rapid development stage. Furthermore, its influence is larger in the damage rapid development stage than the damage stable development stage.

Acknowledgements This paper is an extended version of a published conference paper Li et al. (2017), and this paper gets its funding from Project (51734007) supported by National Natural Science Foundation of China. We would also like to acknowledge the editor-in-chief, editors and the anonymous reviewers for their valuable comments, which have greatly improved this paper.

Open Access This article is distributed under the terms of the Creative Commons Attribution 4.0 International License (http://crea tivecommons.org/licenses/by/4.0/), which permits unrestricted use, distribution, and reproduction in any medium, provided you give appropriate credit to the original author(s) and the source, provide a link to the Creative Commons license, and indicate if changes were made.

\section{References}

Bahaaddini M, Sharrock G, Hebblewhite BK (2013) Numerical investigation of the effect of joint geometrical parameters on the mechanical properties of a non-persistent jointed rock mass under uniaxial compression. Comput Geotech 49:206-225

Camones LAM, Vargas EA, Figueiredo RP (2013) Application of the discrete element method for modeling of rock crack propagation and coalescence in the step-path failure mechanism. Eng Geol 153:80-94

Cao RH, Cao P, Fan X (2016a) An experimental and numerical study on mechanical behavior of ubiquitous-joint brittle rock-like specimens under uniaxial compression. Rock Mech Rock Eng 49:4319-4338

Cao RH, Cao P, Lin H (2016b) Mechanical behavior of brittle rocklike specimens with pre-existing fissures under uniaxial loading: experimental studies and particle mechanics approach. Rock Mech Rock Eng 49:763-783

Cheng H, Zhou XP, Zhu J (2016) The effects of crack openings on crack initiation, propagation and coalescence behavior in rocklike materials under uniaxial compression. Rock Mech Rock Eng 49:3481-3494

Fan X, Kulatilake PHSW, Chen X (2015) Mechanical behavior of rock-like jointed blocks with multi-non-persistent joints under uniaxial loading: a particle mechanics approach. Eng Geol 190:17-32

Lee H, Jeon S (2011) An experimental and numerical study of fracture coalescence in pre-cracked specimens under uniaxial compression. Int J Solids Struct 48:979-999

Lei XL, Masuda K, Nishizawa O (2004) Detailed analysis of acoustic emission activity during catastrophic fracture of faults in rock. J Struct Geol 26:247-258

Li YP, Wan YH, Chen LZ (2004) Experimental research on preexisting cracks in marble under compression. Chin J Geotech Eng 26:120-124

Li SH, Cheng XY, Liu C (2017) Effect law of damage characteristics of rock similar material with pre-existing cracks. IOP Conf Ser Mater Sci Eng 269:012011

Manouchehrian A, Sharifzadeh M, Marji MF (2014) A bonded particle model for analysis of the flaw orientation effect on crack 
propagation mechanism in brittle materials under compression. Arch Civ Mech Eng 14:40-52

Nasseri MH, Rao KS, Ramamurthy T (1997) Failure mechanism in schistose rocks. Int J Rock Mech Min Sci 34:219.e1-219.e15

Niandou H, Shao JF, Henry JP (1997) Laboratory investigation of the mechanical behavior of Tournemire shale. Int J Rock Mech Min Sci 34:3-16

Park CH, Bobet A (2009) Crack coalescence in specimens with open and closed flaws: a comparison. Int J Rock Mech Min Sci 46:819-829

Scholz CH (1968) Experimental study of the fracturing process in brittle rock. J Geophys Res 73:1447-1454

Tang CA, Xu XH (1990) Evolution and propagation of material defects and Kaiser effect function. J Seismol Res 13:203-213

Yang SQ, Dai YH, Han LJ (2009) Uniaxial compression experimental research on deformation and failure properties of brittle marble specimen with pre-existing fissures. Chin J Rock Mech Eng 28:2391-2404
Zhao XD, Chen CH, Liu JP (2008) Experimental study on AE activity characteristics of different rock samples. J Northeast Univ Nat Sci 29:1633-1636

Zhao YL, Wan W, Wang WJ (2013) Fracture experiments materials on ordered multi-crack body in rock-like under uniaxial compression and numerical simulation of wing cracks. Chin $\mathbf{J}$ Geotech Eng 35:2097-2108

Zhao YL, Zhang LY, Wang WJ (2016) Cracking and stress-strain behavior of rock-like material containing two flaws under uniaxial compression. Rock Mech Rock Eng 49:2665-2687

Zhou XP, Cheng H, Feng YF (2014) An experimental study of crack coalescence behavior in rock-like materials containing multiple flaws under uniaxial compression. Rock Mech Rock Eng 47:1961-1986

Zuo JP, Pei JL, Liu JF (2011) Time-space evolution mechanism in failure process of coal-rock combined body. Chin J Rock Mech Eng 30:1564-1570 